\title{
Expression and clinical significance of serum MMP-7 and PTEN levels in patients with acute myeloid leukemia
}

\author{
JIANG WU ${ }^{1}$ and $\mathrm{YU} \mathrm{SONG}^{2}$ \\ ${ }^{1}$ Department of Hematology, Zhongnan Hospital of Wuhan University, Wuhan, Hubei 430071; \\ ${ }^{2}$ Department of Respiration, The Central Hospital of Wuhan, Wuhan, Hubei 430014, P.R. China
}

Received August 2, 2016; Accepted August 16, 2017

DOI: $10.3892 / 01.2018 .7799$

\begin{abstract}
The aim of this study was to examine the changes of serum matrix metalloproteinase-7 (MMP-7) and phosphatase and tension homolog (PTEN) in patients with acute myeloid leukemia (AML) at different time points following treatment. The levels of serum MMP-7 and PTEN were measured from 80 AML patients with a diagnosis of peripheral blood, immune cell phenotype, and bone marrow puncture cytology examination. Among these, there were 20 cases of complete remission, 20 cases of primary untreated patients, 21 cases of incomplete remission, and 19 cases of relapse after remission. In addition, 20 healthy adults with normal physical examination results were enrolled as the control group. Patients were divided into different groups according to the treatment period. Serum MMP-7 and PTEN levels in patients and the healthy control group were measured using an ELISA. Compared with the control group, the levels of MMP-7 of 20 primary untreated patients were significantly increased $(\mathrm{P}<0.05)$, while there was no significant difference for the levels of PTEN in the incomplete remission group. A comparison between the control and complete remission groups revealed that the levels of MMP-7 and PTEN in the serum samples of 21 cases of patients with incomplete remission were significantly increased $(\mathrm{P}<0.05)$. In addition, the content of MMP-7 in 19 patients in relapse after remission group was significantly higher $(\mathrm{P}<0.05)$ than that of the complete remission and healthy control groups, while the levels of serum PTEN did not show significant changes. In conclusion, the level of serum MMP-7 and PTEN in AML patients was closely related to the clinical stage and the degree of disease. The combination of MMP-7 and PTEN may
\end{abstract}

Correspondence to: Dr Jiang Wu, Department of Hematology, Zhongnan Hospital of Wuhan University, 169 Donghu Road, Wuhan, Hubei 430071, P.R. China

E-mail: pgvmue623046231@163.com

Key words: acute myeloid leukemia, matrix metalloproteinase-7, phosphatase and tension homolog provide theoretical support for the accurate diagnosis, understanding of efficacy, prognosis and improvement of survival rate of AML.

\section{Introduction}

Leukemia is a malignant tumor of the blood. Excessive proliferation, blocked differentiation, and disorder of apoptosis are features of malignant cells of leukemia that arrest at various stages of differentiation of bone marrow cells. The main clinical manifestations of this disease include anemia, hemorrhage, fever, and organ infiltration (1,2). Acute myeloid leukemia (AML) is a hematopoietic stem/progenitor cell malignant disease. Primitive and immature myeloid cell hyperplasia in bone marrow and peripheral blood constitute the primary feature, and clinical manifestations include anemia, bleeding, infection, fever, organ invasion and metabolic abnormalities (2). Most AML cases are acute with poor prognosis. If AML is not treated in time, it often becomes life threatening. The disease accounts for $30 \%$ of childhood leukemia (3-5). The focus of current research was to investigate the pathogenesis of leukemia and achieve the greatest degree of treatment for leukemia. In recent years, it has been found that angiogenesis plays an important role in leukemia, which affects the sensitivity of the body to chemotherapy. Some investigators consider that anti-angiogenesis therapy is to become a new treatment of leukemia. Angiogenesis is a complex process. It has been confirmed that many factors can regulate angiogenesis, such as phosphatase and tension homolog (PTEN), IL-1, IL-6, IL-8, cyclooxygenase-2, and matrix metalloproteinase-7 (MMP-7) (6-10).

PTEN is encoded by phosphatase and tension homolog gene (10). Additionally, PTEN is one of the many genes that inhibit cell proliferation (11). It was previously confirmed that MMP-7 is highly expressed in gastric, colon, lung and ovarian cancer (12-15), and closely associated with angiogenesis. Other authors have identified the presence of MMP-7 in tumors of the blood system (16). Specifically, the role of MMP-7 in the treatment of AML and its association with angiogenesis is not well known, and the measurement of the level of MMP-7 in the serum of AML patients is rare in China (17).

On the basis of previous studies, the current study examined the expression level of MMP-7 in patients with AML and its clinical significance, in order to provide a theoretical basis for the targeted treatment of AML. 


\section{Subjects and methods}

Subjects. In total, 80 patients with AML who were treated at the Department of Hematology of Zhongnan Hospital of Wuhan University (Wuhan, China) from September 2013 to June 2014, were randomly selected ( 3 cases of M0, 38 cases of M2, 5 cases of M4, 14 cases of M5), including 19 cases of relapse, 20 cases of primary untreated patients, 21 cases of patients with incomplete remission, and 20 cases of complete remission. The diagnosis and treatment of patients were according to a previous study (2). The exclusion criteria were as follows: Heart, liver and kidney dysfunction, infection, autoimmune diseases and other malignancies. There were 42 male and 21 female subjects, 6-72 years of age, with a median age of 36 years. Twenty subjects with normal physical examination were included in the control group; 15 male and 5 female subjects, aged $18-50$ years, with a median age of 35 years. The study was approved by the Ethics Committee of Zhongnan Hospital of Wuhan University and informed consents were signed by the patients and/or guardians.

Instruments. Instruments used in the experiments included GeneAmp ${ }^{\circledR} 9700$ PCR system (Applied Biosystems, Foster City, CA, USA), Centrifuge 5415D, PB3002-S Electronic Balance (Mettler Toledo, Columbus, OH, USA), 96-well plate, TL-5.0 Desk Centrifuge, Micropipette (Eppendorf, Hamburg Germany), NanoDrop1000 Spectrophotometer and SpeedVac Vacuum Centrifugal Concentration system (both from Thermo Fisher Scientific, Inc., Waltham, MA, USA), NimbleGen HX1 Mixer and NimbleGen Elution system (both from Roche NimbleGen, Inc., Madison, WI, USA), pH meter ( $\Phi 71$; Bio-Rad Laboratories, Inc, Hercules, CA, USA), Electric Thermostatic Water Bath Box (WS2-280-79) and Vortex (both from Beijing Medical Equipment Factory, Beijing, China) and Magnetic Stirrer (JB-3; Shanghai Leici Instrument Factory, Shanghai, China).

Main reagents. The reagents used were as follows: Enzymelinked immunosorbent assay (ELISA) kit for human MMP-7 (Shanghai Elisa Biotech Co., Shanghai, China), and ELISA kit for human PTEN (Booster Bioengineering Co., Ltd., Wuhan, China) (3). Supporting reagents used in the blood cell analyzer were provided by Mindray (Shenzhen, China).

\section{Methods}

Baseline characteristics. The medical history of 80 AML patients and 20 healthy control subjects was obtained. Clinicopathological characteristics including sex, age, height, weight, smoking history, drinking history, history of radiation exposure, blood glucose and blood pressure were recorded.

ELISA. For detection, the samples, and standard samples were incubated with horseradish peroxidase (HRP)-labeled antibodies. The plate was then thoroughly cleaned. Substrate TMB was used to develop color. Under the catalytic action of peroxidase, TMB became blue. Absorbance was measured at $450 \mathrm{~nm}$. The specific concentrations of the samples were then determined.

Sample processing method. Whole blood samples were obtained and kept at room temperature for $2 \mathrm{~h}$ or placed at $4^{\circ} \mathrm{C}$ overnight. Serum samples were centrifuged at $1,650 \mathrm{x} \mathrm{g}$ for $20 \mathrm{~min}$. A certain volume of supernatant was extracted. The specimens were preserved at -20 or $-80^{\circ} \mathrm{C}$ until use. Repeated freeze-thaw was strictly avoided.

To obtain plasma, EDTA or heparin were selected as the anticoagulant. Within 30 min after sample collection, centrifugation was performed at $2-8^{\circ} \mathrm{C}, 1,650 \mathrm{x}$ g for $30 \mathrm{~min}$. The specimens were preserved at -20 or $-80^{\circ} \mathrm{C}$ until use. Repeated freeze-thaw was strictly avoided.

For other biological samples or supernatant of cell culture, samples were centrifuged at $1,650 \mathrm{x}$ g for $20 \mathrm{~min}$. After extraction of a certain volume of supernatant, the test commenced. The specimen was then stored at -20 or $-80^{\circ} \mathrm{C}$. Repeated freeze-thaw was strictly avoided.

Determination of serum MMP-7 and PTEN levels. Standard samples $(50 \mu \mathrm{l})$ and the samples to be tested were added to the well, followed by HRP-labeled antibodies $(100 \mu \mathrm{l})$. The ELISA plate was incubated in a $37^{\circ} \mathrm{C}$ incubator for $60 \mathrm{~min}$. The antibodies were discarded and the plate was washed 3 times with PBS. The substrate TMB $(50 \mu 1 \mathrm{~A}+50 \mu 1 \mathrm{~B})$ was added and the plate was incubated in the dark at $37^{\circ} \mathrm{C}$ for $15 \mathrm{~min}$. The reaction was stopped with $50 \mu 1$ stop solution. The OD was measured at a wavelength of $450 \mathrm{~nm}$. The actual OD value was calculated by measured OD value minus the OD value of blank well. A standard curve was plotted, and the levels of MMP-7 and PTEN were calculated.

Statistical analysis. The current study used SPSS 17.0 (SPSS, Inc., Chicago, IL, USA) for statistical analysis. Measurement data were expressed as means \pm standard deviation (SD) and compared using a Student's t-test. The comparison among groups was analyzed by one way of variance, and the Pearson correlation analysis was used to analyze the correlation between the data. $\mathrm{P}<0.05$ indicated that the difference was statistically significant.

\section{Results}

Comparison of baseline data between AML patients and healthy control (mean $\pm S D$ ). The statistical analysis of the hemogram data of the AML group and healthy control revealed that primary untreated patients did not achieve complete remission, and the leucocyte count $\left(1 \times 10^{9} / 1\right)$, absolute value of lymphocyte $\left(1 \times 10^{9} / 1\right)$, monocyte absolute value $\left(1 \times 10^{9} / 1\right)$, and neutrophil absolute value $\left(1 \times 10^{9} / 1\right)$ of the group of relapse after remission were significantly higher $(\mathrm{P}<0.05)$ than those of the complete remission group and the control group, while the hemoglobin level, red blood cell count and platelet count were not significantly different (Table I and Fig. 1).

Serum MMP-7 levels in AML patients. The levels of MMP-7 in $80 \mathrm{AML}$ patients and 20 healthy control subjects were measured by ELISA. Compared with the control group, the levels of serum MMP-7 were significantly increased $(\mathrm{P}<0.05)$ in 20 patients with primary untreated AML, while there was no significant difference in the PTEN levels when compared with the incomplete remission group. Compared with the control group and complete remission group, both the serum levels of MMP-7 and PTEN in the samples of 21 patients with 
Table I. Eighty cases of acute myeloid leukemia patients and 20 cases of normal blood index (mean \pm standard deviation).

\begin{tabular}{|c|c|c|c|c|c|c|c|c|}
\hline Group & $\begin{array}{l}\text { No. of } \\
\text { cases } \\
(\mathrm{N})\end{array}$ & $\begin{array}{l}\text { Hemoglobin } \\
(\mathrm{g} / \mathrm{l})\end{array}$ & $\begin{array}{l}\text { Red blood } \\
\text { cell count } \\
\left(1 \times 10^{12} / 1\right)\end{array}$ & $\begin{array}{l}\text { Platelet } \\
\text { count } \\
\left(1 \times 10^{9} / 1\right)\end{array}$ & $\begin{array}{c}\text { Leucocyte } \\
\text { count } \\
\left(1 \times 10^{9} / 1\right)\end{array}$ & $\begin{array}{l}\text { Lymphocyte } \\
\text { absolute } \\
\text { value } \\
\left(1 \times 10^{9} / 1\right)\end{array}$ & $\begin{array}{c}\text { Absolute } \\
\text { value of } \\
\text { mononuclear } \\
\text { cells }\left(1 \times 10^{9} / 1\right)\end{array}$ & $\begin{array}{c}\text { Neutrophil } \\
\text { absolute } \\
\text { value } \\
\left(1 \times 10^{9} / 1\right)\end{array}$ \\
\hline Primary untreated & 20 & $9.7 \pm 4.64$ & $3.5 \pm 6.4$ & $101.2 \pm 23.5$ & $15.4 \pm 8.6$ & $10.2 \pm 2.5$ & $0.92 \pm 0.75$ & $8.74 \pm 3.26$ \\
\hline $\begin{array}{l}\text { Complete } \\
\text { remission }\end{array}$ & 20 & $12.7 \pm 2.4$ & $4.2 \pm 2.1$ & $185.7 \pm 12.6$ & $7.3 \pm 2.4$ & $4.6 \pm 3.1$ & $0.54 \pm 0.22$ & $4.37 \pm 1.25$ \\
\hline $\begin{array}{l}\text { Incomplete } \\
\text { remission }\end{array}$ & 21 & $10.7 \pm 1.4$ & $4.3 \pm 1.7$ & $199.4 \pm 21.7$ & $10.4 \pm 1.4$ & $9.8 \pm 1.3$ & $0.82 \pm 0.33$ & $6.27 \pm 2.14$ \\
\hline $\begin{array}{l}\text { Relapse after } \\
\text { remission }\end{array}$ & 19 & $9.7 \pm 10.9$ & $4.8 \pm 1.6$ & $190.4 \pm 28.3$ & $9.8 \pm 2.1$ & $9.6 \pm 2.7$ & $0.87 \pm 0.21$ & $8.26 \pm 1.06$ \\
\hline Control group & 20 & $11.8 \pm 3.5$ & $5.0 \pm 1.5$ & $201.4 \pm 23.9$ & $6.8 \pm 3.6$ & $5.5 \pm 3.3$ & $0.48 \pm 0.73$ & $4.22 \pm 0.89$ \\
\hline $\mathrm{F}$ value & - & 0.86 & 0.97 & 0.97 & 2.24 & 1.02 & 1.22 & 1.05 \\
\hline P-value & & $>0.05$ & $>0.05$ & $>0.05$ & $<0.05$ & $<0.05$ & $<0.05$ & $<0.05$ \\
\hline
\end{tabular}

There was no significant difference in the hemoglobin, red blood cell count and platelet count of the primary untreated group, incomplete remission group, and relapse after remission group $(\mathrm{P}>0.05)$.

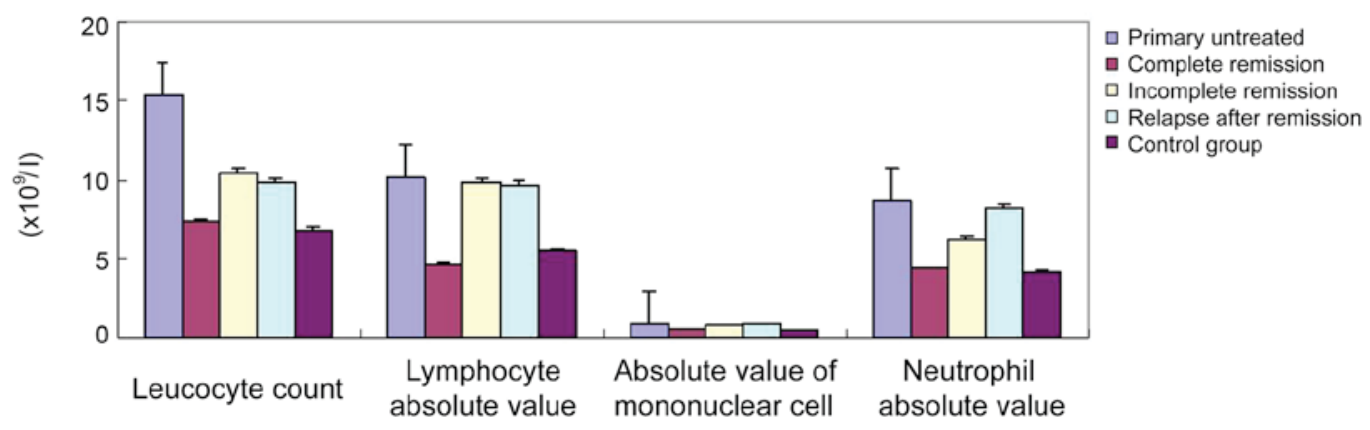

Figure 1. The counts of leucocytest $\left(1 \times 10^{9} / 1\right)$, lymphocytes $\left(1 \times 10^{9} / 1\right)$, monocytes $\left(1 \times 10^{9} / 1\right)$ and neutrophils $\left(1 \times 10^{9} / 1\right)$ of primary untreated group, incomplete remission group and relapse after remission group were significantly higher than those of the complete remission group and the control group, and the differences were statistically significant $(\mathrm{P}<0.05)$.

incomplete remission were significantly increased $(\mathrm{P}<0.05)$. In addition, the levels of MMP-7 in 19 patients of relapse after remission were significantly higher than those of the complete remission group and healthy control $(\mathrm{P}<0.05)$, and the serum PTEN levels were not significantly altered. Serum MMP-7 and PTEN levels are shown in Table II, and the standard curve is shown in Fig. 2.

Correlation analysis between MMP-7 and PTEN. For the Pearson correlation analysis, MMP-7 was considered the dependent variable, and PTEN the independent variable. It was found that $\mathrm{r}=0.37, \mathrm{P}=0.46$, i.e., the levels of MMP-7 and PTEN were not correlated ( $\mathrm{P}>0.05)$ (Fig. 3). Thus, the serum levels of MMP-7 and PTEN did not affect each other.

Combined diagnostic efficacy of PTEN and MMP-7 in serum. To determine the significance of MMP-7 combined with PTEN in the diagnosis of different stages of AML patients. It was found that MMP-7 combined with PTEN significantly improved the diagnostic performance of the different treatment stages of AML patients, and the area under ROC curve was 0.902 (Fig. 4).

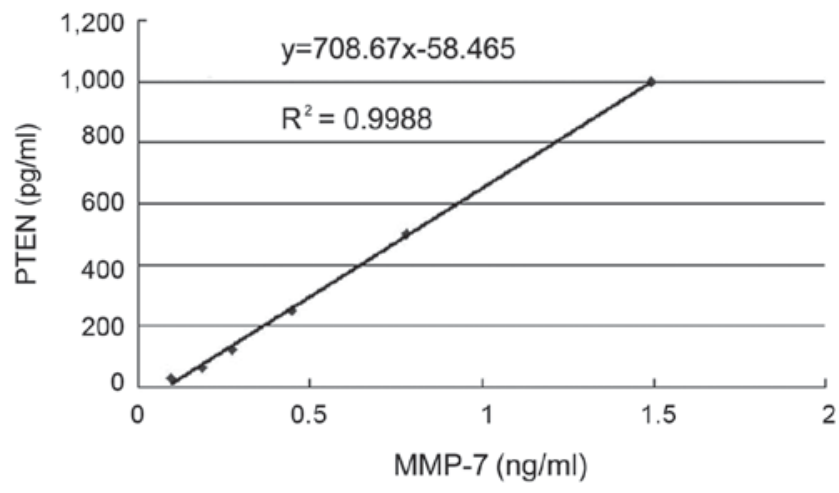

Figure 2. Correlation analysis between serum MMP-7 level and PTEN level: $\mathrm{y}=708.67 \mathrm{x}-58.465$. MMP-7, matrix metalloproteinase-7; PTEN, phosphatase and tension homolog.

Comparison of survival rate. We followed up for 80 AMP patients for 3 months after treatment. Both serum levels of PTEN and MMP-7 were detected. Patient survival was compared. The results showed that after complete remission, higher serum MMP-7 levels correlated with worse prognosis 
Table II. Serum MMP-7 and PTEN levels (mean \pm standard deviation).

\begin{tabular}{lcll}
\hline Group & $\begin{array}{c}\text { No. of } \\
\text { cases }\end{array}$ & $\begin{array}{c}\text { PTEN } \\
(\mathrm{pg} / \mathrm{ml})\end{array}$ & $\begin{array}{c}\text { MMP-7 } \\
(\mathrm{ng} / \mathrm{ml})\end{array}$ \\
\hline Primary untreated & 20 & $298.45^{\mathrm{a}, \mathrm{b}}$ & $2.887^{\mathrm{a}, \mathrm{b}}$ \\
Complete remission & 20 & 166.84 & 1.52 \\
Incomplete remission & 21 & $270.81^{\mathrm{a}, \mathrm{b}}$ & $2.50^{\mathrm{a}, \mathrm{b}}$ \\
Relapse after remission & 19 & $123.90^{\mathrm{a}, \mathrm{b}}$ & $2.35^{\mathrm{a}, \mathrm{b}}$ \\
Control & 20 & 137.55 & 1.45 \\
\hline
\end{tabular}

Compared with the control group, ${ }^{\text {a }}<<0.01$; compared with the complete remission group, ${ }^{b} \mathrm{P}<0.01$. MMP-7, matrix metalloproteinase-7; PTEN, phosphatase and tension homolog.

A

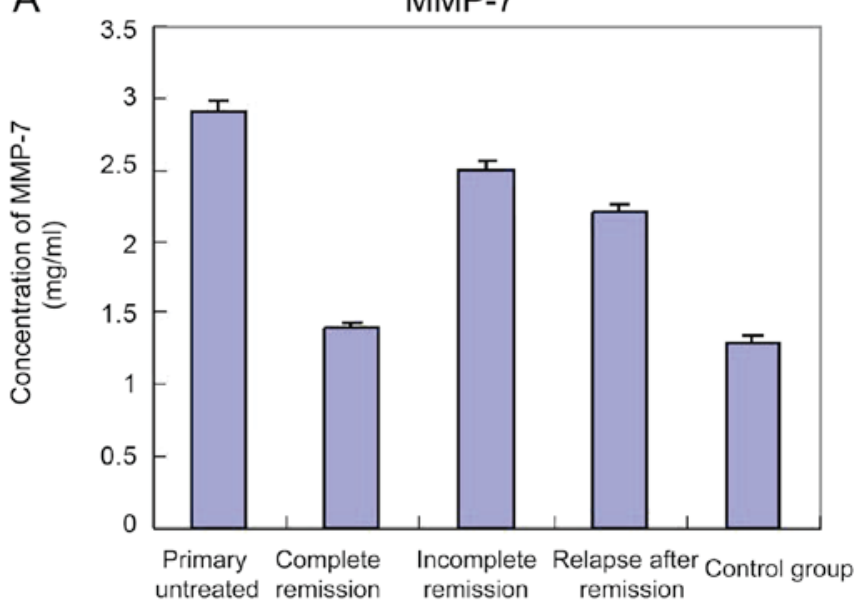

B

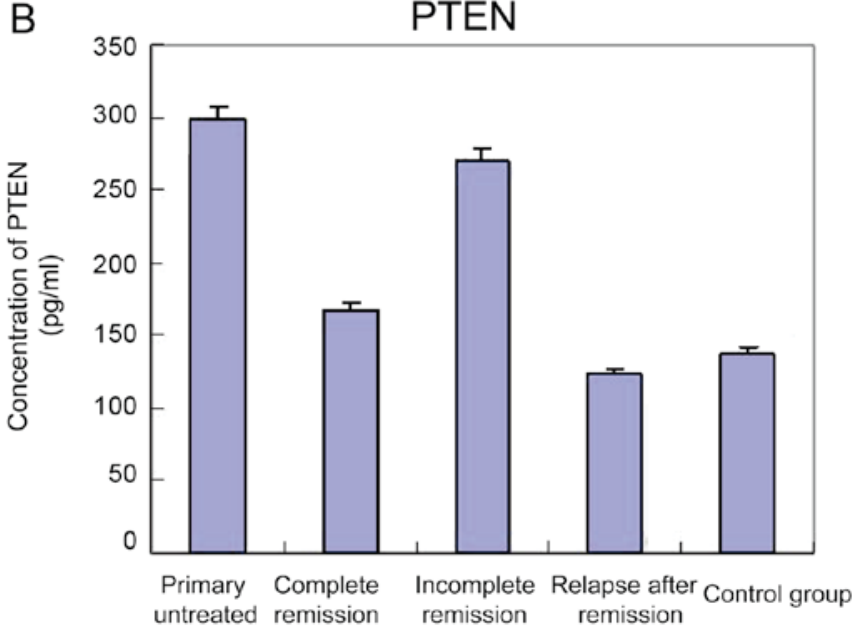

Figure 3. Serum (A) MMP-7 and (B) PTEN levels in AML patients. Compared with the control group, the serum levels of MMP-7 in 20 patients with primary untreated AML were significantly increased, and the difference was statistically significant $(\mathrm{P}<0.05)$. The level of PTEN was not significant different compared with that of the incomplete remission group $(\mathrm{P}>0.05)$. Compared with the control and complete remission groups, the levels of MMP-7 and PTEN in 21 patients with incomplete remission were significantly increased $(\mathrm{P}<0.05)$. In addition, the levels of MMP-7 in 19 patients in the relapse after remission group were significantly higher than those of the complete remission and healthy control groups $(\mathrm{P}<0.05)$, and the serum levels of PTEN were not significantly different $(\mathrm{P}>0.05)$. MMP-7, matrix metalloproteinase-7; PTEN, phosphatase and tension homolog; AML, acute myeloid leukemia.

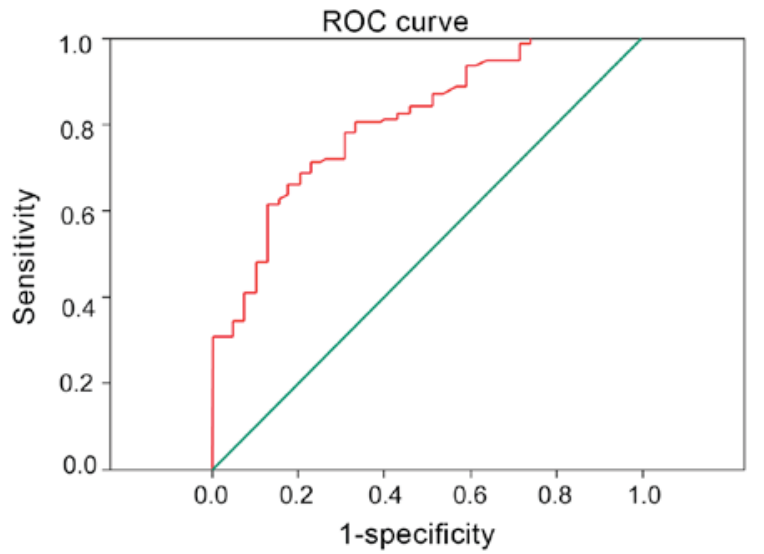

Figure 4. Detection of MMP-7 and PTEN may significantly improve the diagnosis of the different treatment stages of AML patients, and the area under ROC curve was 0.902. MMP-7, matrix metalloproteinase-7; PTEN, phosphatase and tension homolog; AML, acute myeloid leukemia.

A

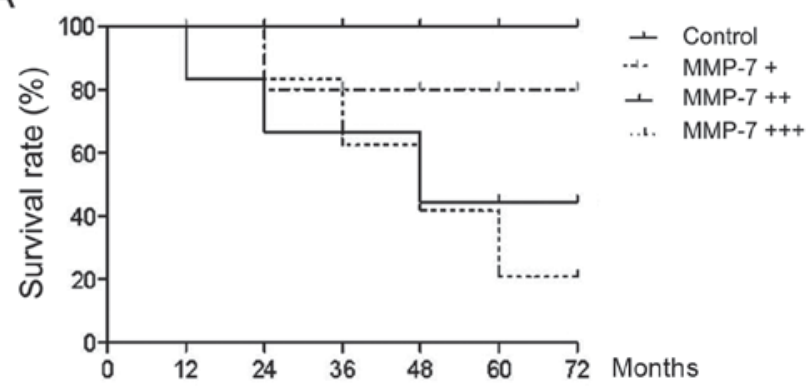

B

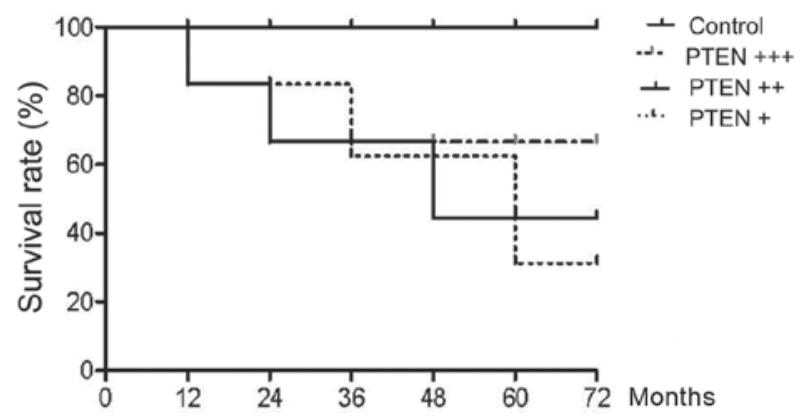

Figure 5. The follow-up period was three months, both serum levels of (A) MMP-7 and (B) PTEN were detected, and the average values were calculated. The results showed that a higher level of serum MMP-7 was associated with worse prognosis, shorter survival, whereas a higher PTEN level was associated with better the prognosis after complete remission. MMP-7, matrix metalloproteinase-7; PTEN, phosphatase and tension homolog.

and shorter survival while higher PTEN levels indicated better prognosis (Fig. 5).

\section{Discussion}

Small blood vessels in the tissue surrounding the tumor are invaded by germination and tumor tissues, known as tumor angiogenesis. This phenomenon is very common in hematologic malignancies. Previous findings showed that the former neovascularization was significantly less in patients with monoclonal immunoglobulin than patients with multiple 
myeloma disease (18). At the same time, in the treatment of multiple myeloma, thalidomide was widely used in clinical practice and the drug resistance on neovascularization was also an important mechanism. This conclusion was confirmed in the corresponding research in patients with acute lymphoblastic leukemia (ALL) $(18,19)$.

Folkman and Hochberg suggested that the growth and metastasis of solid tumors depended on the generation of new blood vessels (19). A number of studies showed the overexpression of angiogenic factors (VEGF, MMP-7, PDGF, TGF- $\beta$, bFGF, PLGF, IGF) in solid tumors, and that inhibition of the expression of angiogenic factors could be used in the treatment of malignant tumors $(20,21)$. However, studies on the expression of the angiogenic factor gene in non-solid tumors and its anti-angiogenesis therapy are limited (19). The role of neovascularization in malignant hematologic diseases has been widely accepted. Many clinical trials and experiments confirmed that patients with multiple myeloma, lymphoma and leukemia were accompanied by angiogenesis $(22,23)$. Numerous newborn blood vessels in bone marrow and the levels of angiogenic factors in patients showed an increasing trend. These were closely related to the prognosis and progression of the disease. By taking child patients with ALL as the research focus and comparing them with patients without bone marrow metastasis of lymphoma and patients with solid tumors, McKee et al (24) investigated newborn blood vessels in the bone marrow of the patients and found that the blood vessel density of ALL patients was significantly higher than that of patients without bone marrow metastasis of lymphoma and patients with solid tumors. At the same time, the researchers who built the three-dimensional model of the blood vessels in the bone marrow found that in the micro-vascular imaging, the leukemia and control groups, respectively, showed arborization and single-straight shape (25). By detection of urinary BFGF and fibroblast growth factor, the researchers found that urinary BFGF levels in children with disease onset were significantly higher than those after complete remission group (25). Results of the present study showed that in primary untreated AML patients, serum MMP-7 was significantly higher than that in the healthy controls. By contrast, the level of MMP-7 was decreased significantly in the complete remission group compared with the control group. Differences were not statistically significant $(\mathrm{P}>0.05)$. This was similar to the results of previous studies, which undertook research on the bone marrow from 20 adult AML patients, and compared the above samples with those of normal subjects (25). Those authors eventually found that angiogenesis in the bone marrow of AML patients was significantly increased in comparison with the control group.

However, we also found that in the diagnosis of AML, MMP-7 exhibited sensitivity without specificity. This was because other types of leukemia may also express MMP-7 to a certain degree (26). Therefore, we further detected the serum level of PTEN in patients. Previous studies found that PTEN may be used as a marker for the diagnosis of some solid tumors, especially in the evaluation of metastasis and prognosis of malignant tumor (27). Previous findings showed that the level of PTEN was significantly increased in the early stage of cervical cancer, although the level of PTEN was significantly decreased with the increasing degree of malignancy (27).
PTEN played a role by competing with tyrosine kinase as a tumor suppressor and played a regulatory role by preventing cell growth and mitosis (28). However, the underlying mechanism remains to be clarified. In human solid tumors, this role has also not been confirmed. Our study found that in primary untreated AML patients, both MMP-7 and PTEN levels were significantly increased, while in patients with relapse after remission, MMP-7 levels were significantly increased, while PTEN levels were normal or even low. Given these reasons, we hypothesized that in the early stage of cancer, MMP-7 was activated by certain factors to promote the occurrence of carcinogenesis. At the same time, the tumor suppressor gene PTEN was also activated by inhibiting tumor cell mitosis to suppress tumor cell proliferation and distant metastasis. However, during disease progression, the proto-oncogene was activated by various signaling pathways and the release of inflammatory cytokines, which may inhibit the PTEN signaling pathway. As a result, the protective effect of tumor suppressor gene PTEN was weakened, and tumor metastasis was promoted, albeit this hypotheseis remains to be confirmed (27-29).

To sum up, PTEN and MMP-7 exert a synergistic effect in the generation of new blood vessels. Detection of the expression level of PTEN and MMP-7 in AML patients at different stages of treatment was clinically significant for the diagnosis of AML and targeted therapy.

\section{References}

1. Gallogly MM and Lazarus HM: Midostaurin: An emerging treatment for acute myeloid leukemia patients. J Blood Med 7: 73-83, 2016.

2. Grain A, Sirvent A, Strullu M, Françoise M, Mohty M, Guillaume T, Chevallier P and Rialland F: Sustained responses after clofarabine-based sequential allogeneic stem cell transplantation in children with high-risk, relapse and/or refractory acute myeloid leukemia or juvenile myelomonocytic leukemia: A study on behalf of the French society of bone marrow transplantation or cell therapy (SFGM-TC). Leuk Lymphoma 57: 2937-2941, 2016.

3. Yung KW, Yung TT, Chung CY, Tong GT, Liu Y, Henderson J, Welbeck D and Oseni S: Principles of cancer staging. Asian Pac J Surg Oncol 1: 1-16, 2015.

4. Sterling B, Cole R, Jen KK and Shieh JS: Surgical oncology in the elderly. Asian Pac J Surg Oncol 1: 83-100, 2015.

5. Lee R, Yeung AW, Hong SE, Brose MS and Michels DL: Principles of medical oncology. Asian Pac J Surg Oncol 1: 39-46, 2015.

6. Buchanan J and Tirado CA: A t $(16 ; 21)(\mathrm{p} 11 ; \mathrm{q} 22)$ in acute myeloid leukemia (AML) resulting in fusion of the FUS/TLS and ERG genes: A review of the literature. J Assoc Genet Technol 42: 24-33, 2016.

7. Presta M, Dell'Era P, Mitola S, Moroni E, Ronca R and Rusnati M: Fibroblast growth factor/fibroblast growth factor receptor system in angiogenesis. Cytokine Growth Factor Rev 16: 159-178, 2005.

8. Hajime M, Shuichi Y, Makoto N, Masanori Y, Ikuko K, Atsushi K, Mutsuo S and Keiichi T: Inhibitory effect of 4-methylesculetin on hyaluronan synthesis slows the development of human pancreatic cancer in vitro and in nude mice. Int J Cancer 120: 2704-2709, 2007.

9. de Bont ES, Rosati S, Jacobs S, Kamps WA and Vellenga E: Increased bone marrow vascularization in patients with acute myeloid leukaemia: A possible role for vascular endothelial growth factor. Br J Haematol 113: 296-304, 2001.

10. Milella M, Falcone I, Conciatori F, Cesta Incani U, Del Curatolo A, Inzerilli N, Nuzzo CM, Vaccaro V, Vari S, Cognetti F and Ciuffreda L: PTEN: Multiple functions in human malignant tumors. Front Oncol 5: 24, 2015.

11. Hopkins BD, Hodakoski C, Barrows D, Mense SM and Parsons RE: PTEN function: The long and the short of it. Trends Biochem Sci 39: 183-190, 2014.

12. Yonemura Y, Endou Y, Fujita H, Fushida S, Bandou E, Taniguchi K, Miwa K, Sugiyama K and Sasaki T: Role of MMP-7 in the formation of peritoneal dissemination in gastric cancer. Gastric Cancer 3: 63-70, 2000. 
13. Kioi M, Yamamoto K, Higashi S, Koshikawa N, Fujita K and Miyazaki K: Matrilysin (MMP-7) induces homotypic adhesion of human colon cancer cells and enhances their metastatic potential in nude mouse model. Oncogene 22: 8662-8670, 2003.

14. Safranek J, Pesta M, Holubec L, Kulda V, Dreslerova J, Vrzalova J, Topolcan O, Pesek M, Finek J and Treska V: Expression of MMP-7, MMP-9, TIMP-1 and TIMP-2 mRNA in lung tissue of patients with non-small cell lung cancer (NSCLC) and benign pulmonary disease. Anticancer Res 29: 2513-2517, 2009.

15. Chang MC, Chen CA, Chen PJ, Chiang YC, Chen YL, Mao TL, Lin HW, Lin Chiang WH and Cheng WF: Mesothelin enhances invasion of ovarian cancer by inducing MMP-7 through MAPK/ERK and JNK pathways. Biochem J 442: 293-302, 2012.

16. Koskensalo S, Mrena J, Wiksten JP, Nordling S, Kokkola A, Hagström J and Haglund C: MMP-7 overexpression is an independent prognostic marker in gastric cancer. Tumour Biol 31: $149-155,2010$.

17. Mitsiades N, Yu WH, Poulaki V, Tsokos M and Stamenkovic I: Matrix metalloproteinase-7-mediated cleavage of Fas ligand protects tumor cells from chemotherapeutic drug cytotoxicity. Cancer Res 61: 577-581, 2001.

18. Sanna M, Caocci G, Vacca A, Piras E, Orrù F, La Nasa G: Daunorubicin, cytarabine, and cladribine regimen plus radiotherapy and donor lymphocyte infusion for extramedullary relapse of acute myeloid leukemia after hematopoietic stem cell transplantation. Case Rep Hematol 2013: 258028, 2013.

19. Folkman J and Hochberg M: Self-regulation of growth in three dimensions. J Exp Med 138: 745-753, 1973.

20. Poon RT, Fan ST and Wong J: Clinical implications of circulating angiogenic factors in cancer patients. J Clin Oncol 19 $1207-1225,2001$

21. Jones LW, Fels DR, West M, Allen JD, Broadwater G, Barry WT, Wilke LG, Masko E, Douglas PS, Dash RC, et al: Modulation of circulating angiogenic factors and tumor biology by aerobic training in breast cancer patients receiving neoadjuvant chemotherapy. Cancer Prev Res (Phila) 6: 925-937, 2013.
22. Hussong JW, Rodgers GM and Shami PJ: Evidence of increased angiogenesis in patients with acute myeloid leukemia. Blood 95 309-313, 2000.

23. Mineo M, Garfield SH, Taverna S, Flugy A, De Leo G, Alessandro R and Kohn EC: Exosomes released by K562 chronic myeloid leukemia cells promote angiogenesis in a Src-dependent fashion. Angiogenesis 15: 33-45, 2012.

24. McKee C, Perez-Cruet M, Chavez F and Chaudhry GR: Simplified three-dimensional culture system for long-term expansion of embryonic stem cells. World J Stem Cells 7: 1064-1077, 2015.

25. Bieker R, Padró T, Kramer J, Steins M, Kessler T, Retzlaff S, Herrera F, Kienast J, Berdel WE and Mesters RM: Overexpression of basic fibroblast growth factor and autocrine stimulation in acute myeloid leukemia. Cancer Res 63: 7241-7246, 2003.

26. Cheng HW, Li CW, Chan KY, Au HY, Chan PF, Sin YC, Szeto Y and Sham MK: End-of-life characteristics and palliative care provision for elderly patients suffering from acute myeloid leukemia. Support Care Cancer 23: 111-116, 2015.

27. Burgucu D, Guney K, Sahinturk D, Ozbudak IH, Ozel D, Ozbilim G and Yavuzer U: Tbx3 represses PTEN and is over-expressed in head and neck squamous cell carcinoma. BMC Cancer 12: 481, 2012.

28. Li L, Wang LX, Xu GL, Yang F, Gao QL, Niu H, Shi B and Jiang X: Bio-informatics analysis of renal carcinoma gene matrix metalloproteinase-7. Indian J Cancer 53: 13-18, 2016.

29. Mieszało K, Ławicki S and Szmitkowski M: The utility of metalloproteinases (MMPs) and their inhibitors (TIMPs) in diagnostics of gynecological malignancies. Pol Merkur Lekarski 40: 193-197, 2016 (In Polish). International (CC BY-NC-ND 4.0) License. 